\title{
Sixteen years and counting: an update on leptin in energy balance
}

\author{
Laurent Gautron and Joel K. Elmquist
}

Department of Internal Medicine, Division of Hypothalamic Research, The University of Texas Southwestern Medical Center, Dallas, Texas, USA.

\begin{abstract}
Cloned in 1994, the $o b$ gene encodes the protein hormone leptin, which is produced and secreted by white adipose tissue. Since its discovery, leptin has been found to have profound effects on behavior, metabolic rate, endocrine axes, and glucose fluxes. Leptin deficiency in mice and humans causes morbid obesity, diabetes, and various neuroendocrine anomalies, and replacement leads to decreased food intake, normalized glucose homeostasis, and increased energy expenditure. Here, we provide an update on the most current understanding of leptin-sensitive neural pathways in terms of both anatomical organization and physiological roles.
\end{abstract}

\section{Introduction}

The nervous system regulates energy balance at the organismal level by constantly adjusting energy intake, expenditure, and storage. The influence of the nervous system over metabolic functions was first suggested at the beginning of the 20th century when excessive adiposity was associated with pituitary tumors and injury to the hypothalamus (1). However, it was not until the 1940s that selective surgical lesions of certain hypothalamic areas were found to result in extreme obesity or leanness in rats $(2,3)$. Over the last few decades, numerous discoveries substantially extended our understanding of the neural control of metabolism. However, it is safe to say that none were more important than the cloning of the $o b$ gene by Friedman and colleagues in 1994 (4). The $o b$ gene encodes the protein leptin, which is a hormone produced and secreted by the white adipose tissue, and consequently, its circulating levels are closely related to body fat mass $(5,6)$. Leptin deficiency in mice homozygous for a mutant $o b$ gene ( $o b / o b$ mice) causes morbid obesity, diabetes, and various neuroendocrine anomalies, and leptin replacement leads to decreased food intake, normalized glucose homeostasis, and increased energy expenditure (7-10). Several splice variants of the leptin receptor have been identified, and the "short forms" are widely expressed in multiple tissues (11). The "long form" of the leptin receptor encodes a protein with a longer cytoplasmic domain (OB-Rb) that is highly expressed in particular sites within the CNS (refs. 10, 12, and Table 1). The short forms of the leptin receptor are also present within the CNS (11), but OB-Rb is sufficient for leptin actions on metabolism $(13,14)$. OB-Rb is a type 1 cytokine receptor, which stimulates the JAK/STAT3 pathway $(15)$ and PI3K $(16,17)$. Leptin induces transcriptional changes of several genes via the JAK/STAT3 pathway, and rapid changes in cellular activity and membrane potential may underlie the acute actions of leptin (18). While actions of this hormone in peripheral tissues have been identified, studies in genetically modified mice have demonstrated that leptin action only in the CNS is sufficient to regulate body weight, feeding, energy expenditure, and glucose metabolism (13, 19-21).

Since leptin is clearly not the only metabolic signal acting on the brain, the range of its effects on behavior, metabolism, and endocrinology is truly remarkable. In addition, leptin has effects

Conflict of interest: The authors have declared that no conflict of interest exists. Citation for this article: J Clin Invest. 2011;121(6):2087-2093. doi:10.1172/JCI45888. on reproduction and immunity that are beyond the scope of this article. The goal of this article is to provide an update on the most current understanding of leptin-sensitive neural pathways both in terms of anatomical organization and physiological roles.

\section{Physiological roles of rising and falling levels of leptin}

To forestall starvation, mammals have developed sophisticated biological mechanisms of energy conservation and repartitioning to respond to low levels of energy availability. Starvation leads to a rapid decrease in serum leptin level prior to the depletion of adipose tissue mass (22). Ahima and colleagues hypothesized that this fall in leptin was a starvation signal that may activate the aforementioned starvation response programs (22). Consequently, endocrine, behavioral, and autonomic responses induced by fasting can be blunted by repletion of leptin during the fast (22). Thus, the changing level of circulating leptin is a key signal to the brain regarding energy stores, and a fall in leptin results in the stereotyped responses characteristic of starvation. Low leptin levels can also be the result of rare genetic disorders such as lipodystrophies and congenital leptin deficiency $(23,24)$. Leptin administration corrects many of the metabolic anomalies seen in lipodystrophic patients including diabetes, dyslipidemia, and hepatic steatosis $(25,26)$ and completely reverses the obese phenotype of leptindeficient individuals $(27,28)$.

On the other end of the spectrum of energy balance, overnutrition is becoming increasingly prevalent and, strikingly, it is predicted that individuals who are considered clinically obese will represent $10 \%$ of the world adult population by 2015 (29). Although genetic predispositions to obesity exist, hyperphagia is admitted to be the most direct cause for these unprecedented rates of obesity (30). As a logical consequence of their increased fat mass, obese individuals systemically show elevated serum leptin levels $(6,31)$. However, for reasons that are not fully understood, obese individuals do not show diminished appetite and increased energy expenditure, as would be predicted based on their increased leptin levels $(6,31)$. Likewise, in animal models, high-fat diet-induced hyperleptinemia aggravates weight gain and metabolic anomalies (32-34). In the face of these observations, researchers elaborated the concept of leptin resistance, which refers to the inability of obese individuals and high-fat-fed animals to respond to endogenous or exogenous leptin (35). The cellular mechanisms initiating leptin resistance is an active area of study, and the theoretical and experimental basis has recently been reviewed in detail (35). 


\section{Table 1}

Anatomical distribution of leptin-expressing sites and known neurochemical identity and afferent projections of $\mathrm{OB}-\mathrm{Rb}$-expressing neurons in the adult rodent brain

\begin{tabular}{|c|c|c|c|c|}
\hline \multirow{2}{*}{$\begin{array}{l}\text { OB-Rb levels } \\
\text { High expressior }\end{array}$} & \multirow[t]{2}{*}{ Leptin-sensitive sites } & \multirow[t]{2}{*}{ Neurochemical identity } & \multirow[t]{2}{*}{ Identified target sites } & \multirow[t]{2}{*}{ References } \\
\hline & & & & \\
\hline & PMV & CART & POA, AVPV & $12,40,91,113$ \\
\hline & $\mathrm{ARH}$ & POMC/CART, AgRP/NPY & LHA, PVH, NTS & $12,58,91,114-116$ \\
\hline & DMH & - & PVH, ARH, POA, PAG, PVT, BST, PC & 12,39 \\
\hline & VMH & Dyn & SPVZ & $12,91,117,118$ \\
\hline & MEPO & - & - & 91 \\
\hline \multicolumn{5}{|c|}{ Moderate expression } \\
\hline & $\mathrm{RCA}$ & POMC/CART & Spinal cord & 61 \\
\hline & LHA ant & - & VTA, DR, PAG, SNC, DMH, LHA & 77,119 \\
\hline & $\mathrm{PH}$ & - & - & 12,91 \\
\hline & EW & - & - & 91 \\
\hline & PAG & - & - & 91,120 \\
\hline & VTA & TH & $\mathrm{CeA}$ & 91,121 \\
\hline & DR & - & - & 12,91 \\
\hline & NTS & $\mathrm{GLP1}^{A}, \mathrm{POMC}$ & - & $118,120,122-124$ \\
\hline & LPB & CCK & - & 91,118 \\
\hline & $\mathrm{DG}, \mathrm{CA} 1, \mathrm{CA} 3^{\mathrm{C}}$ & - & - & 12,91 \\
\hline & SNC & TH & - & 12,91 \\
\hline & Cortices and claustrum ${ }^{\mathrm{C}}$ & - & - & 12,91 \\
\hline \multicolumn{5}{|l|}{ Low expression } \\
\hline & $\mathrm{DHA}$ & - & - & 91 \\
\hline & $\mathrm{Pe}$ & - & - & 12,91 \\
\hline & PVNpv D & $\mathrm{TRH}$ & - & 66,125 \\
\hline & APD & - & - & 123 \\
\hline & LSV & - & - & 91 \\
\hline & DMV & - & - & 123 \\
\hline
\end{tabular}

AP, area postrema; AVPV, anteroventral periventricular nucleus; BST, bed nucleus of the stria terminalis; CA, Ammon's horn; CART, cocaine- and amphetamine-regulated transcript; CeA, central amygdala; DG, dentate gyrus; DHA, dorsal area of the hypothalamus; DR, dorsal raphe; Dyn, dynorphin; EW, Edinger-Westphal nucleus; GLP1, glucagon-like peptide 1; LHA ant; anterior part of the LHA; LPB, lateral parabrachial nucleus; LSV, ventral nucleus of the lateral septum; MEPO, medial preoptic nucleus; PAG, periaqueductal area; PC, pre-coeruleus; Pe, periventricular hypothalamus; PH, posterior hypothalamus; POA, preoptic area; PVNpv, parvicellular part of the paraventricular nucleus of the hypothalamus; PVT, paraventricular thalamus; RCA, retrochiasmatic area; SNC, substantia nigra pars compacta; SPVZ, subparaventricular zone; TH, tyrosine hydroxylase; TRH, thyrotropin-releasing hormone; PMV, ventral premammillary nucleus. AOnly in mouse. ${ }^{B}$ Controversial. ${ }^{C}$ Obrb mRNA is expressed, but signaling activity remains to be shown. ${ }^{\mathrm{D} O n l y}$ in rat. Dashes indicate "unidentified."

\section{Mapping leptin-sensitive neural pathways}

The distribution and chemical identity of neurons able to respond to leptin have been well described in rodents (Table 1). To date, leptin-sensitive neurons located in the arcuate nucleus of the hypothalamus (ARH) have probably received the most attention from investigators in the field. The ARH contains proopiomelanocortin (POMC) neurons, which produce the anorectic peptide $\alpha$-melanocyte-stimulating hormone $(\alpha \mathrm{MSH})$, an agonist of the melanocortin-4 receptor (MC4R) $(36,37)$. Uniquely, the ARH also contains neurons that produce the orexigenic peptides neuropeptide Y (NPY) and agouti-related peptide (AgRP). The latter acts as an endogenous MC4R antagonist or inverse agonist (38). Persuasive evidence has established that the activity (both transcriptional and membrane potential) of both populations of neurons is oppositely regulated by leptin $(18,36)$. The neurochemical identity of leptin-sensitive neurons outside the ARH is still somewhat rudimentary but has begun to be deciphered using traditional neuroanatomical methods and genetically modified reporter mice. Similarly, genetically modified mice have emerged as particularly valuable tools to assess the axonal projections of identified leptin-sensitive neurons $(39,40)$. Table 1 summarizes the distribution, neurochemical identity, and axonal projections of leptin-sensitive sites in the rodent brain.

\section{Identification and segregation of the leptin-sensitive pathways regulating energy balance}

Glucose homeostasis. Early studies suggested that diabetes characteristically seen in $o b / o b$ mice was not solely due to hyperphagia and increased adiposity (41). In support of this, recent insulinclamp studies revealed that leptin can modify hepatic glucose production by simultaneously increasing gluconeogenesis and decreasing glycogenolysis in rats and mice (42-44), suggesting that leptin has antidiabetic actions. Leptin (alone or in combination with insulin) can dramatically improve glycemic control in animal models of type 1 diabetes (45-47). Interestingly, the chronic intracerebral administration of leptin (48) and virally mediated overexpression of leptin within the brain $(49,50)$ both exert similar beneficial effects on glucose homeostasis. Consistent with the idea that the antidiabetic action of leptin is centrally mediated, mice with OB-Rb expression restricted to the brain are capable of maintaining normal glucose homeostasis $(14,20,51)$.

Some of the leptin effects on gluconeogenesis may be MC4R dependent (52), thus implicating ARH neurons in the antidiabetic actions of leptin. Whereas the Cre-mediated deletion of OB-Rb only in POMC neurons results in mild obesity and no major 


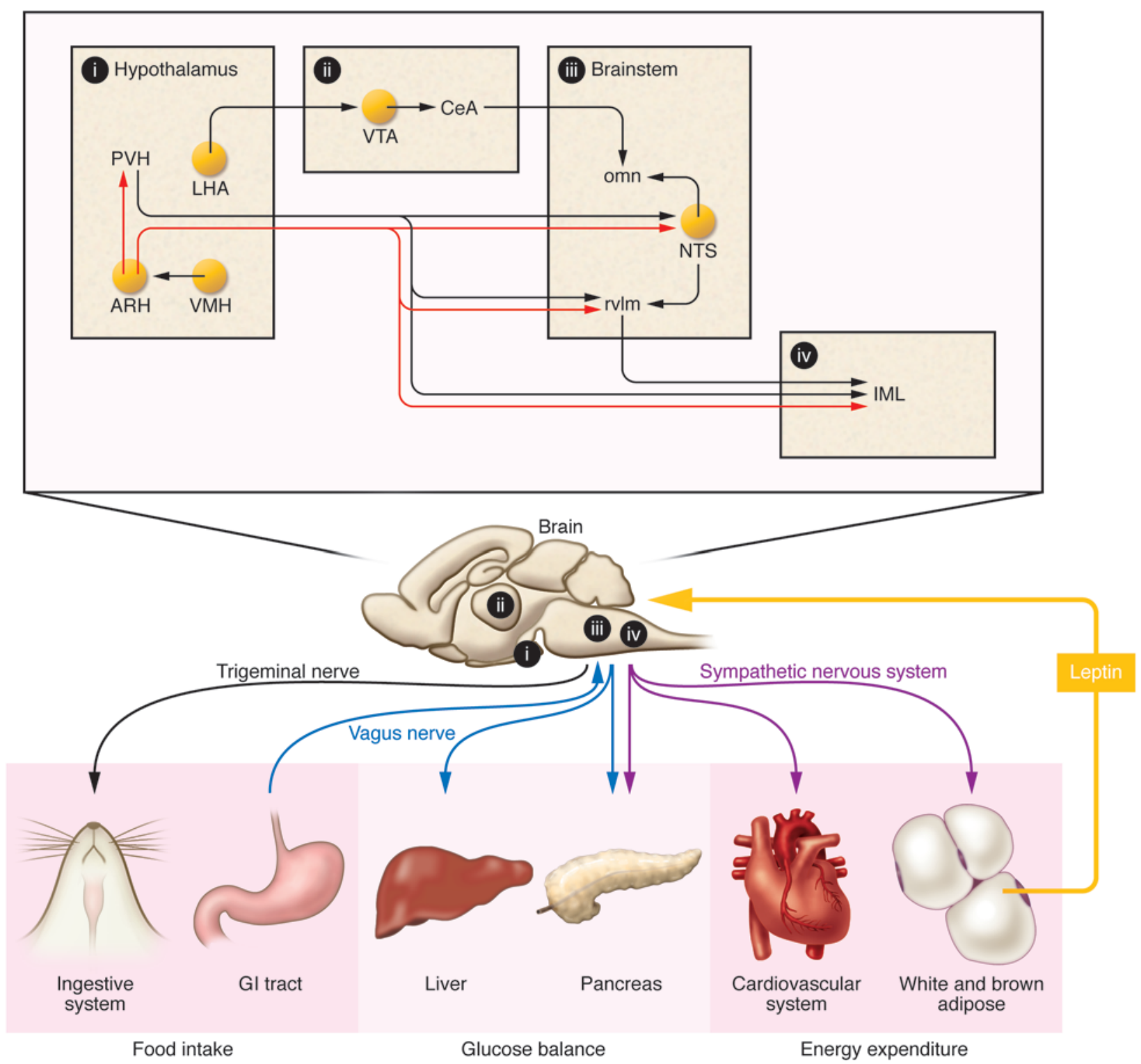

Figure 1

Simplified neuroanatomical model of leptin action within the CNS in the regulation of metabolic functions. Leptin secreted by adipocytes is transported across the blood-brain barrier to act on specific leptin-sensitive brain sites (yellow circles). In particular, leptin exerts opposite effects on the activity of $\mathrm{ARH}$ neurons that produce $\alpha \mathrm{MSH}$ and AgRP, two important endogenous ligands of the MC4R (MC4R-dependent pathways appear in red). In response to leptin, these peptides are released in brain sites important in the control of glucose homeostasis, energy expenditure, and feeding within the hypothalamus and brainstem. Recent studies also found that leptin signaling in the VTA and LHA plays a critical role in feeding and reward processes. Finally, different branches of the autonomic nervous system make connections with peripheral tissues (liver, pancreas, etc.) and ultimately mediate leptin actions on peripheral metabolic processes. Overall, leptin modulates the activity of intricate neural circuits that are distributed through many different brain regions. Tg, trigeminal nerve; X, vagus nerve; SNS, sympathetic nervous system; omn, oral masticatory nuclei; rvlm, rostroventral medulla; $\mathrm{CeA}$, central amygdala.

effect on glucose homeostasis in male mice and impaired glucose tolerance in females $(53,54)$, mice lacking $\mathrm{OB}-\mathrm{Rb}$ in both POMC and AgRP neurons show hyperinsulinemia (55). More strikingly, rescuing leptin receptor expression only in ARH neurons of $\mathrm{OB}-\mathrm{Rb}$-deficient rodents completely normalizes their glucose and insulin levels (20), improves their hepatic insulin sensitivity, and reduces gluconeogenesis (51). Together, these studies clearly support the key role of ARH neurons in mediating the action of leptin to regulate glucose homeostasis and insulin levels (Figure 1). At least in mice, these effects can be largely independent of modifications in feeding and body weight.

Based on the known importance of the parasympathetic outflow to the liver in regulating glucose production in several different species $(56,57)$, it has been hypothesized that the vagus nerve is an important efferent arm of the nervous system mediating the antidiabetic actions of leptin. For example, the effects of leptin 
on hepatic glucose fluxes is abrogated when the hepatic branch of the vagus nerve is sectioned in rats (51). Although the leptinresponsive cell group mediating these responses remains to be identified, this effect could be mediated by POMC neurons innervating the dorsovagal complex (58), a brain region that contains the dorsal motor nucleus of the vagus nerve (DMV) (Figure 1). Many DMV neurons express MC4R and innervate the hepatic artery in mice (59), thus providing an anatomical link from leptinsensitive pathways to the liver.

It is also important to note that the sympathetic nervous system is a potentially important player in the antidiabetic action of leptin. For example, Fan and colleagues (60) demonstrated that the insulin-lowering effects of central leptin are blocked by the concomitant administration of $\alpha$-adrenergic antagonist. This is in accordance with the fact that leptin-sensitive POMC neurons located in the rostral ARH project to pre-ganglionic sympathetic neurons located in the intermediolateral column (IML) (61). The latter neurons are in an ideal position to regulate the sympathetic outflow to tissues important in glucose homeostasis (i.e., pancreatic islets) (Figure 1).

Leptin can also regulate glycogenolysis in a MC4R-independent manner (52), implying that neurons outside the ARH are important in the antidiabetic actions of leptin. Along these lines, it is interesting that leptin administered into the ventromedial nucleus of the hypothalamus $(\mathrm{VMH})$ stimulates glucose uptake in peripheral tissues (62-64). In addition, the loss of the leptin signaling inhibitor SOCS3 only in VMH neurons leads to improved glucose homeostasis (65). Surprisingly, the effect of intra-VMH leptin on glucose uptake is MC4R dependent (64) and requires an intact sympathetic nervous system (62). This could mean that VMH leptin-sensitive neurons regulate glucose metabolism via an anatomical relay involving POMC neurons (Figure 1). Importantly, the neurons responsible for the MC4R-independent effect of leptin on glucose homeostasis have not been identified. The paraventricular hypothalamus (PVH) is a possible candidate, as it sends a direct projection to pre-ganglionic autonomic neurons. Although few PVH neurons express OB-Rb in rodents (66), many leptin-sensitive sites (e.g., dorsomedial nucleus of the hypothalamus $[\mathrm{DMH}]$ ) are connected to the $\mathrm{PVH}$, and future experiments are warranted to delineate the contribution of these brain sites to the antidiabetic action of leptin.

Food intake. The existence of hypothalamic centers regulating hunger and satiety has been appreciated for decades. This simple but attractive concept has been gradually replaced by more elaborate neuroanatomical models, which have incorporated the concept of the distributed nature of the neuronal networks that control food intake (67). Leptin can modulate several different aspects of feeding behavior, including meal size $(68,69)$, food reward $(70,71)$, and food preference $(72,73)$. Collectively, these observations suggest that the neural circuits underlying leptin actions on food intake are highly complex. In agreement with such a view, the microinjection of leptin directly into several different brain sites distributed in the hypothalamus $(\mathrm{ARH}, \mathrm{VMH}$, lateral hypothalamic area [LHA]), midbrain (ventral tegmental area [VTA]), and brainstem (nucleus of the solitary tract [NTS]) can reduce food intake (74-77). Initially, the exact role of leptin signaling in each of these sites was extrapolated based their known involvement in specific aspects of feeding behavior. More recently, genetic approaches have been employed to identity the exact brain sites that are important for leptin regulatory effects on feeding behavior.
ARH neurons play a key role in regulating feeding $(36,37)$. While leptin reduces feeding when directly administered into the ARH $(58,75)$, numerous studies have demonstrated that leptin signaling in ARH neurons reduces only short-term, but not long-term, food intake. First, the deletion of OB-Rb and STAT3 specifically from POMC and/or AgRP neurons in genetically modified mice produces no significant alteration of long-term food intake (53, $55,78,79)$. Second, mice genetically engineered to overexpress SOCS3 only in POMC neurons show a blunted response to the acute anorectic effects of leptin (80). Third, mice lacking key molecules downstream of the OB-Rb signaling pathway (i.e., STAT3, $\mathrm{PI} 3 \mathrm{~K})$ in AgRP or POMC neurons similarly show attenuated response to acute but not chronic leptin $(79,81)$. Finally, rescuing $\mathrm{OB}-\mathrm{Rb}$ expression in $\mathrm{ARH}$ neurons of $\mathrm{OB}-\mathrm{Rb}-$ deficient rodents only modestly reduces their hyperphagia $(19,20)$.

The role of leptin in the control of short-term feeding is interesting, given that ingestive behavior is commonly perturbed in obese states (82). The effect of leptin on short-term feeding likely involves projections from ARH neurons to brainstem sites involved in satiation mechanisms (Figure 1). It has been noted that leptin can amplify the anorectic effects of cholecystokinin (CCK) (8385 ), a prototypical satiation factor produced by intestinal cells in response to meal ingestion. The anorectic effects of CCK are primarily mediated by vagal afferents innervating the intestines which are connected to the NTS, its primary relay within the brainstem. There is also now convincing evidence that leptin potentiates visceral neurotransmission received at the level of the NTS (86-88). This effect could be partly mediated by the stimulation of ARH melanocortin neurons, which project to the NTS, since mice lacking OB-Rb in both AgRP and POMC neurons show increased meal sizes and blunted response to the early anorectic effects of leptin (55). In addition, leptin directly injected into the dorsal vagal complex enhances CCK-induced anorectic effects (89), and knocking down leptin receptor expression in the dorsal vagal complex of rats eliminates CCK-induced feeding suppression (90). Collectively, these data suggest that leptin acts on a distributed network of neurons in the brainstem and hypothalamus to regulate feeding, and reciprocal connections between these two brain regions assure proper coordination of food intake over longer periods of time.

Leptin signaling is also present in neurons classically implicated in reward, such as dopaminergic neurons in the VTA (ref. 91 and Figure 1). Microinjection of leptin into this site does reduce feeding, and knocking down OB-Rb only in the VTA leads to increased feeding (71). Another site important in food reward is the LHA, which for many years was referred to as the "hunger center" because discrete lesions at this site result in severe cachexia and loss of appetite (2). Leptin reduces feeding when directly administered into the LHA, and neurons bearing OB-Rb in the LHA send projections to the VTA (77). Reward-seeking behaviors can be elicited in rats trained to press a lever that stimulates an electrode implanted in the LHA (self-stimulation experiments) (92). Interestingly, this type of experiment has been used to demonstrate that intracerebral leptin administration can reduce the effectiveness of reward mechanisms (93). Together, these studies suggest that leptin can directly regulate reward mechanisms at the level of both the VTA and the LHA. Needless to say, food reward cannot be dissociated from satiety, taste, and homeostatic needs, and numerous psychological and environmental factors may also influence food reward. Overall, the area of research on the link between leptin and reward still remains in its infancy. 
Body weight. Body weight control is exceptionally complicated and is determined by the sum of multiple metabolic processes including whole body energy expenditure, body temperature, locomotor activity, cardiorespiratory parameters, and lipogenesis. All the aforementioned physiological parameters are under the control of the sympathetic nervous system, and observed changes in these parameters are often considered to be indirect measures of sympathetic outflow. Hence, it is often difficult to dissociate the reciprocal influence that the aforementioned parameters have on one another. Several lines of evidence suggest that leptin directly regulates energy expenditure by stimulating the activity of the sympathetic nervous system to its target tissues (94-97). Although preganglionic sympathetic neurons do not express OB-Rb, leptin-sensitive neurons are found in several brain sites connected to the IML (e.g., PVH, NTS, etc.), and therefore leptin signaling in any of these sites can potentially influence sympathetic outflow (Figure 1). The contribution of the melanocortin system to leptin effects on energy expenditure and body weight is supported by numerous pharmacological studies (98-100). A number of parallel genetic studies similarly demonstrated that locomotor activity, temperature, or energy expenditure are changed in mice with modified expression of OB-Rb or its signaling molecular partners in $\mathrm{ARH}$ neurons $(17,20,55,79,101,102)$.

The VMH appears to be another important site of action in the control of energy expenditure. For example, mice that lack $\mathrm{OB}-\mathrm{Rb}$ in $\mathrm{VMH}$ neurons show more severe obesity and lowered energy expenditure on a high-fat diet $(103,104)$. While the exact pathway linking VMH neurons to the sympathetic nervous system remains to be worked out, the VMH appears to be an essential component of a circuit necessary to resist high-fat diet-induced obesity. Of note, injection of leptin into the NTS also stimulates energy expenditure (100). However, knockdown of leptin receptor expression in the NTS in rats had no effect on energy expenditure, activity, or body temperature (90). The latter contradictory results illustrate that there are still important gaps in our understanding of leptin effects on body weight, and future experiments are warranted to systematically map leptin signaling in nuclei with known sympathetic efferent connections (e.g., NTS, rostral ventrolateral medulla, etc.).

\section{Perspectives}

Over the past 16 years, researchers have described with exquisite detail the neural pathways that contribute to leptin actions on metabolism (at least in rodents). It appears from these studies that each of the actions of leptin on metabolism is supported by neurons distributed in the hypothalamus, midbrain, and brainstem. Moreover, several recent studies have demonstrated that leptin-sensitive neural pathways are remarkably plastic in response to changes in leptin levels in rodents during postnatal development and adult- hood (105-107). This suggests that morphological changes progressively develop in the brain during obesity, and further inquiry into the cellular mechanisms linking obesity, neural plasticity, and food craving is urgently needed. As mentioned before, new applications for leptin therapy have been suggested based on animal research, including the treatment of type 1 diabetes (46). Finally, recent evidence suggests that certain gut peptides (e.g., ghrelin) act in an additive manner with leptin to regulate energy balance (108), which may lead to the future development of combination therapies to enhance leptin sensitivity in obese states.

Our current understanding of leptin action on energy balance is largely based on animal research and, therefore, one may wonder how much we have really learned about leptin action in the human brain. Most of our understanding of leptin action in the human brain derives from brain imaging techniques $(109,110)$. Brain activity can be monitored in individuals receiving either leptin or placebo during the viewing of food-related stimuli. These types of studies established that leptin modulates the activity of regions involved in the neural representations of hunger and satiety and the anticipation of reward including the ventral striatum, insula, parietal and temporal cortex, and prefrontal cortex regions $(109,110)$. Rosenbaum and colleagues (111) also showed that dieting-induced weight loss changes the activity of many of the aforementioned brain regions, and most of these can be reversed by leptin administration. Strikingly, these leptin-induced brain changes are correlated with enhanced weight loss and catabolic processes (112), which suggests that leptin administration in obese individuals can be useful in the context of weight loss maintenance. These exciting data warrant further studies on leptin action in the human brain.

In conclusion, it is safe to say that the control of energy balance is one of the most exciting areas of neuroscience research when one notes the breadth of the field, which spans studies of single genes, genetically modified animal models, and humans with identified single-gene mutations that cause profound defects in energy balance control. This field of study will certainly continue to advance our understanding of metabolism and will give the medical community new opportunities to design more efficient therapies to prevent and/or cure obesity as well as other metabolic and eating disorders.

\section{Acknowledgments}

The Obesity Review Series is supported in part by unrestricted educational grants from Merck \& Co. and the Life Sciences Institute of the University of Michigan.

Address correspondence to: Joel K. Elmquist, 5323 Harry Hines Blvd., Dallas, Texas 75390-8591, USA. Phone: 214.648.8621; Fax: 214.648.5612; E-mail: joel.elmquist@UTSouthwestern.edu.
1. Bray GA. Historical framework for the development of ideas about obesity. In: Bray GA, Bouchard C, James WPT, eds. Handbook of Obesity. 2nd ed. Boca Raton, Florida, USA: CRC Press; 1998:6.

2. Anand BK, Brobeck JR. Localization of a "feeding center" in the hypothalamus of the rat. Proc Soc Exp Biol Med. 1951;77(2):323-324.

3. Hetherington AW, Ranson SW. Hypothalamic lesions and adiposity in the rat. Anat Rec. 1940; 78(2):149-172.

4. Zhang Y, Proenca R, Maffei M, Barone M, Leopold L, Friedman JM. Positional cloning of the mouse obese gene and its human homologue. Nature.
1994;372(6505):425-432.

5. Frederich RC, Hamann A, Anderson S, Lollmann B, Lowell BB, Flier JS. Leptin levels reflect body lipid content in mice: evidence for diet-induced resistance to leptin action. Nat Med. 1995;1(12):1311-1314.

6. Maffei M, et al. Leptin levels in human and rodent: measurement of plasma leptin and ob RNA in obese and weight-reduced subjects. Nat Med. 1995;1(11):1155-1161.

7. Campfield LA, Smith FJ, Guisez Y, Devos R, Burn $\mathrm{P}$. Recombinant mouse OB protein: evidence for a peripheral signal linking adiposity and central neural networks. Science. 1995;269(5223):546-549.
8. Halaas JL, et al. Weight-reducing effects of the plasma protein encoded by the obese gene. Science. 1995;269(5223):543-546.

9. Pelleymounter MA, et al. Effects of the obese gene product on body weight regulation in ob/ob mice. Science. 1995;269(5223):540-543.

10. Chua SC Jr, et al. Phenotypes of mouse diabetes and rat fatty due to mutations in the OB (leptin) receptor. Science. 1996;271(5251):994-996.

11. Tartaglia LA, et al. Identification and expression cloning of a leptin receptor, OB-R. Cell. 1995; 83(7):1263-1271.

12. Elmquist JK, Bjorbaek C, Ahima RS, Flier JS, 
Saper CB. Distributions of leptin receptor mRNA isoforms in the rat brain. J Comp Neurol. 1998; 395(4):535-547.

13. de Luca C, et al. Complete rescue of obesity, diabetes, and infertility in $\mathrm{db} / \mathrm{db}$ mice by neuronspecific LEPR-B transgenes. J Clin Invest. 2005 115(12):3484-3493.

14. Kowalski TJ, Liu SM, Leibel RL, Chua SC Jr. Transgenic complementation of leptin-receptor deficiency. I. Rescue of the obesity/diabetes phenotype of LEPR-null mice expressing a LEPR-B transgene. Diabetes. 2001;50(2):425-435.

15. Baumann $\mathrm{H}$, et al. The full-length leptin receptor has signaling capabilities of interleukin 6type cytokine receptors. Proc Natl Acad Sci U S A. 1996;93(16):8374-8378.

16. Niswender KD, Morton GJ, Stearns WH, Rhodes CJ, Myers MG Jr, Schwartz MW. Intracellular signalling. Key enzyme in leptin-induced anorexia. Nature. 2001;413(6858):794-795.

17. Al-Qassab H, et al. Dominant role of the p110beta isoform of PI3K over p110alpha in energy homeostasis regulation by POMC and AgRP neurons. Cell Metab. 2009;10(5):343-354.

18. Williams KW, Scott MM, Elmquist JK. From observation to experimentation: leptin action in the mediobasal hypothalamus. Am J Clin Nutr. 2009;89(3):985S-990S.

19. Morton GJ, et al. Arcuate nucleus-specific leptin receptor gene therapy attenuates the obesity phenotype of Koletsky $(\mathrm{fa}(\mathrm{k}) / \mathrm{fa}(\mathrm{k}))$ rats. Endocrinology. 2003;144(5):2016-2024.

20. Coppari R, et al. The hypothalamic arcuate nucleus: a key site for mediating leptin's effects on glucose homeostasis and locomotor activity. Cell Metab. 2005;1(1):63-72.

21. Cohen P, et al. Selective deletion of leptin receptor in neurons leads to obesity. J Clin Invest. 2001 108(8):1113-1121.

22. Ahima RS, et al. Role of leptin in the neuroendocrine response to fasting. Nature. 1996;382(6588):250-252.

23. Montague CT, et al. Congenital leptin deficiency is associated with severe early-onset obesity in humans. Nature. 1997;387(6636):903-908.

24. Haque WA, Shimomura I, Matsuzawa Y, Garg A. Serum adiponectin and leptin levels in patients with lipodystrophies. J Clin Endocrinol Metab. 2002;87(5):2395.

25. Oral EA, et al. Leptin-replacement therapy for lipodystrophy. N Engl J Med. 2002;346(8):570-578

26. Petersen KF, et al. Leptin reverses insulin resistance and hepatic steatosis in patients with severe lipodystrophy. J Clin Invest. 2002;109(10):1345-1350.

27. Farooqi IS, et al. Beneficial effects of leptin on obesity, T cell hyporesponsiveness, and neuroendocrine/ metabolic dysfunction of human congenital leptin deficiency. J Clin Invest. 2002;110(8):1093-1103.

28. Licinio J, et al. Phenotypic effects of leptin replacement on morbid obesity, diabetes mellitus, hypogonadism, and behavior in leptin-deficient adults. Proc Natl Acad Sci U S A. 2004;101(13):4531-4536.

29. WHO. Overweight and Obesity. Atlanta, Georgia, USA: CDC; 2006

30. Unger RH, Scherer PE. Gluttony, sloth and the metabolic syndrome: a roadmap to lipotoxicity. Trends Endocrinol Metab. 2010;21(6):345-352.

31. Considine RV, et al. Serum immunoreactiveleptin concentrations in normal-weight and obese humans. NEngl J Med. 1996;334(5):292-295.

32. Townsend KL, Lorenzi MM, Widmaier EP. High-fat diet-induced changes in body mass and hypothalamic gene expression in wild-type and leptin-deficient mice. Endocrine. 2008;33(2):176-188.

33. White CL, Whittington A, Barnes MJ, Wang Z, Bray GA, Morrison CD. HF diets increase hypothalamic PTP1B and induce leptin resistance through both leptin-dependent and -independent mechanisms. Am J Physiol Endocrinol Metab. 2009;296(2):E291-E299.
34. Ogus S, Ke Y, Qiu J, Wang B, Chehab FF. Hyperleptinemia precipitates diet-induced obesity in transgenic mice overexpressing leptin. Endocrinology. 2003;144(7):2865-2869.

35. Myers MG Jr, Leibel RL, Seeley RJ, Schwartz MW. Obesity and leptin resistance: distinguishing cause from effect. Trends Endocrinol Metab. 2010;21(11):643-651.

36. Seeley RJ, Drazen DL, Clegg DJ. The critical role of the melanocortin system in the control of energy balance. Annu Rev Nutr. 2004;24:133-149.

37. Cone RD. Studies on the physiological functions of the melanocortin system. Endocr Rev. 2006;27(7):736-749.

38. Lu D, et al. Agouti protein is an antagonist of the melanocyte-stimulating-hormone receptor. Nature. 1994;371(6500):799-802.

39. Gautron L, Lazarus M, Scott MM, Saper CB, Elmquist JK. Identifying the efferent projections of leptin-responsive neurons in the dorsomedial hypothalamus using a novel conditional tracing approach. J Comp Neurol. 2010;518(11):2090-2108.

40. Leshan RL, Louis GW, Jo YH, Rhodes CJ, Munzberg H, Myers MG Jr. Direct innervation of GnRH neurons by metabolic- and sexual odorant-sensing leptin receptor neurons in the hypothalamic ventral premammillary nucleus. J Neurosci. 2009; 29(10):3138-3147.

41. Dubuc PU. The development of obesity, hyperinsulinemia, and hyperglycemia in ob/ob mice. Metabolism. 1976;25(12):1567-1574.

42. Liu L, et al. Intracerebroventricular leptin regulates hepatic but not peripheral glucose fluxes. J Biol Chem. 1998;273(47):31160-31167.

43. Rossetti L, et al. Short term effects of leptin on hepatic gluconeogenesis and in vivo insulin action. J Biol Chem. 1997;272(44):27758-27763.

44. Kamohara S, Burcelin R, Halaas JL, Friedman JM, Charron MJ. Acute stimulation of glucose metabolism in mice by leptin treatment. Nature. 1997;389(6649):374-377.

45. Yu X, Park BH, Wang MY, Wang ZV, Unger RH. Making insulin-deficient type 1 diabetic rodents thrive without insulin. Proc Natl Acad Sci U S A. 2008;105(37):14070-14075

46. Wang MY, et al. Leptin therapy in insulin-deficient type I diabetes. Proc Natl Acad Sci U S A. 2010;107(11):4813-4819.

47. Chinookoswong N, Wang JL, Shi ZQ. Leptin restores euglycemia and normalizes glucose turnover in insulin-deficient diabetes in the rat. Diabetes. 1999;48(7):1487-1492.

48. Fujikawa T, Chuang JC, Sakata I, Ramadori G, Coppari R. Leptin therapy improves insulin-deficient type 1 diabetes by CNS-dependent mechanisms in mice. Proc Natl Acad Sci U S A. 2010; 107(40):17391-17396.

49. Ueno N, Inui A, Kalra PS, Kalra SP. Leptin transgene expression in the hypothalamus enforces euglycemia in diabetic, insulin-deficient nonobese Akita mice and leptin-deficient obese ob/ob mice. Peptides. 2006;27(9):2332-2342.

50. Kojima S, et al. Central leptin gene therapy, a substitute for insulin therapy to ameliorate hyperglycemia and hyperphagia, and promote survival in insulin-deficient diabetic mice. Peptides. 2009;30(5):962-966.

51. German J, et al. Hypothalamic leptin signaling regulates hepatic insulin sensitivity via a neurocircuit involving the vagus nerve. Endocrinology. 2009;150(10):4502-4511.

52. Gutierrez-Juarez R, Obici S, Rossetti L. Melanocortin-independent effects of leptin on hepatic glucose fluxes. J Biol Chem. 2004;279(48):49704-49715.

53. Balthasar $\mathrm{N}$, et al. Leptin receptor signaling in POMC neurons is required for normal body weight homeostasis. Neuron. 2004;42(6):983-991.

54. Shi H, Sorrell JE, Clegg DJ, Woods SC, Seeley RJ.
The roles of leptin receptors on POMC neurons in the regulation of sex-specific energy homeostasis. Physiol Behav. 2010;100(2):165-172.

55. van de Wall E, et al. Collective and individual functions of leptin receptor modulated neurons controlling metabolism and ingestion. Endocrinology. 2008;149(4):1773-1785.

56. Matsuhisa M, et al. Important role of the hepatic vagus nerve in glucose uptake and production by the liver. Metabolism. 2000;49(1):11-16.

57. Cardin S, Walmsley K, Neal DW, Williams PE, Cherrington $\mathrm{AD}$. Involvement of the vagus nerves in the regulation of basal hepatic glucose production in conscious dogs. Am J Physiol Endocrinol Metab. 2002;283(5):E958-E964.

58. Zheng $\mathrm{H}$, et al. A potential role for hypothalamomedullary POMC projections in leptin-induced suppression of food intake. Am J Physiol Regul Integr Comp Physiol. 2010;298(3):R720-R728.

59. Gautron L, Lee C, Funahashi H, Friedman J, Lee $\mathrm{S}$, Elmquist J. Melanocortin-4 receptor expression in a vago-vagal circuitry involved in postprandial functions. J Comp Neurol. 2010;518(1):6-24.

60. Fan W, Dinulescu DM, Butler AA, Zhou J, Marks $\mathrm{DL}$, Cone RD. The central melanocortin system can directly regulate serum insulin levels. Endocrinology. 2000;141(9):3072-3079.

61. Elias CF, et al. Leptin activates hypothalamic CART neurons projecting to the spinal cord. Neuron. 1998;21(6):1375-1385.

62. Haque MS, Minokoshi Y, Hamai M, Iwai M, Horiuchi M, Shimazu T. Role of the sympathetic nervous system and insulin in enhancing glucose uptake in peripheral tissues after intrahypothalamic injection of leptin in rats. Diabetes. 1999; 48(9):1706-1712.

63. Minokoshi Y, Haque MS, Shimazu T. Microinjection of leptin into the ventromedial hypothalamus increases glucose uptake in peripheral tissues in rats. Diabetes. 1999;48(2):287-291.

64. Toda C, et al. Distinct effects of leptin and a melanocortin receptor agonist injected into medial hypothalamic nuclei on glucose uptake in peripheral tissues. Diabetes. 2009;58(12):2757-2765.

65. Zhang R, et al. Selective inactivation of Socs3 in SF1 neurons improves glucose homeostasis without affecting body weight. Endocrinology. 2008;149(11):5654-5661

66. Harris $M$, et al. Transcriptional regulation of the thyrotropin-releasing hormone gene by leptin and melanocortin signaling. J Clin Invest. 2001; 107(1):111-120.

67. Grill HJ, Kaplan JM. The neuroanatomical axis for control of energy balance. Front Neuroendocrinol. 2002;23(1):2-40.

68. Flynn MC, Scott TR, Pritchard TC, Plata-Salaman CR. Mode of action of OB protein (leptin) on feeding. Am J Physiol. 1998;275(1 pt 2):R174-R179.

69. Kahler A, Geary N, Eckel LA, Campfield LA, Smith FJ, Langhans W. Chronic administration of $\mathrm{OB}$ protein decreases food intake by selectively reducing meal size in male rats. Am J Physiol. 1998; 275(1 pt 2):R180-R185

70. Figlewicz DP, Bennett JL, Naleid AM, Davis C, Grimm JW. Intraventricular insulin and leptin decrease sucrose self-administration in rats. Physiol Behav. 2006;89(4):611-616.

71. Hommel JD, et al. Leptin receptor signaling in midbrain dopamine neurons regulates feeding. Neuron. 2006;51(6):801-810.

72. Wetzler S, Jean-Joseph G, Even P, Tome D, LarueAchagiotis C. Acute third ventricular administration of leptin decreases protein and fat in self-selecting rats. Behav Brain Res. 2005;159(1):119-125.

73. Licinio J, et al. Effects of leptin replacement on macro- and micronutrient preferences. Int J Obes (Lond). 2007;31(12):1859-1863.

74. Jacob RJ, et al. The effect of leptin is enhanced by 
microinjection into the ventromedial hypothalamus. Diabetes. 1997;46(1):150-152.

75 . Satoh $\mathrm{N}$, et al. The arcuate nucleus as a primary site of satiety effect of leptin in rats. Neurosci Lett. 1997;224(3):149-152

76. Grill HJ, Schwartz MW, Kaplan JM, Foxhall JS, Breininger J, Baskin DG. Evidence that the caudal brainstem is a target for the inhibitory effect of leptin on food intake. Endocrinology. 2002; 143(1):239-246.

77. Leinninger GM, et al. Leptin acts via leptin receptor-expressing lateral hypothalamic neurons to modulate the mesolimbic dopamine system and suppress feeding. Cell Metab. 2009;10(2):89-98.

78. Xu AW, Ste-Marie L, Kaelin CB, Barsh GS. Inactivation of signal transducer and activator of transcription 3 in proopiomelanocortin (Pomc) neurons causes decreased pomc expression, mild obesity, and defects in compensatory refeeding. Endocrinology. 2007;148(1):72-80.

79. Hill JW, et al. Acute effects of leptin require PI3K signaling in hypothalamic proopiomelanocortin neurons in mice. J Clin Invest. 2008;118(5):1796-1805.

80. Reed AS, Unger EK, Olofsson LE, Piper ML, Myers MG Jr, Xu AW. Functional role of suppressor of cytokine signaling 3 upregulation in hypothalamic leptin resistance and long-term energy homeostasis. Diabetes. 2010;59(4):894-906.

81. Gong L, et al. Signal transducer and activator of transcription- 3 is required in hypothalamic agouti-related protein/neuropeptide Y neurons for normal energy homeostasis. Endocrinology. 2008;149(7):3346-3354.

82. Bellisle F, Le Magnen J. The structure of meals in humans: eating and drinking patterns in lean and obese subjects. Physiol Behav. 1981;27(4):649-658.

83. Barrachina MD, Martinez V, Wang L, WeiJY, Tache Y. Synergistic interaction between leptin and cholecystokinin to reduce short-term food intake in lean mice. Proc Natl Acad Sci U S A. 1997;94(19):10455-10460.

84. Morton GJ, et al. Leptin action in the forebrain regulates the hindbrain response to satiety signals. J Clin Invest. 2005;115(3):703-710.

85. Blevins JE, et al. Forebrain melanocortin signaling enhances the hindbrain satiety response to CCK-8. Am J Physiol Regul Integr Comp Physiol. 2009 296(3):R476-R484.

86. Emond M, Ladenheim EE, Schwartz GJ, Moran TH. Leptin amplifies the feeding inhibition and neural activation arising from a gastric nutrient preload. Physiol Behav. 2001;72(1-2):123-128.

87. Huo L, Maeng L, Bjorbaek C, Grill HJ. Leptin and the control of food intake: neurons in the nucleus of the solitary tract are activated by both gastric distension and leptin. Endocrinology. 2007; 148(5):2189-2197.

88. Wang L, Barachina MD, Martinez V, Wei JY, Tache Y. Synergistic interaction between CCK and leptin to regulate food intake. Regul Pept. 2000;92(1-3):79-85.

89. Williams DL, Baskin DG, Schwartz MW. Hindbrain leptin receptor stimulation enhances the anorexic response to cholecystokinin. Am J Physiol Regul Integr Comp Physiol. 2009;297(5):R1238-R1246.

90. Hayes MR, et al. Endogenous leptin signaling in the caudal nucleus tractus solitarius and area postrema is required for energy balance regulation.
Cell Metab. 2010;11(1):77-83.

91. Scott MM, et al. Leptin targets in the mouse brain. J Comp Neurol. 2009;514(5):518-532.

92. Olds J, Milner P. Positive reinforcement produced by electrical stimulation of septal area and other regions of rat brain. J Comp Physiol Psychol. 1954;47(6):419-427.

93. Fulton S, Woodside B, Shizgal P. Modulation of brain reward circuitry by leptin. Science. 2000; 287(5450):125-128.

94. Haynes WG, Morgan DA, Walsh SA, Mark AL, Sivitz WI. Receptor-mediated regional sympathetic nerve activation by leptin. J Clin Invest. 1997; 100(2):270-278.

95. Overton JM, Williams TD, Chambers JB, Rashotte ME. Central leptin infusion attenuates the cardiovascular and metabolic effects of fasting in rats. Hypertension. 2001;37(2 part 2):663-669.

96. Hausberg M, Morgan DA, Mitchell JL, Sivitz WI, Mark AL, Haynes WG. Leptin potentiates thermogenic sympathetic responses to hypothermia: a receptor-mediated effect. Diabetes. 2002; 51(8):2434-2440.

97. Buettner C, et al. Leptin controls adipose tissue lipogenesis via central, STAT3-independent mechanisms. Nat Med. 2008;14(6):667-675.

98. Satoh N, et al. Satiety effect and sympathetic activation of leptin are mediated by hypothalamic melanocortin system. Neurosci Lett. 1998;249(2-3):107-110.

99. da Silva AA, Kuo JJ, Hall JE. Role of hypothalamic melanocortin 3/4-receptors in mediating chronic cardiovascular, renal, and metabolic actions of leptin. Hypertension. 2004;43(6):1312-1317.

100.Skibicka KP, Grill HJ. Hindbrain leptin stimulation induces anorexia and hyperthermia mediated by hindbrain melanocortin receptors. Endocrinology. 2009;150(4):1705-1711.

101.Kievit P, et al. Enhanced leptin sensitivity and improved glucose homeostasis in mice lacking suppressor of cytokine signaling-3 in POMC-expressing cells. Cell Metab. 2006;4(2):123-132.

102. Mesaros A, et al. Activation of Stat 3 signaling in AgRP neurons promotes locomotor activity. Cell Metab. 2008;7(3):236-248.

103.Dhillon H, et al. Leptin directly activates SF1 neurons in the $\mathrm{VMH}$, and this action by leptin is required for normal body-weight homeostasis. Neuron. 2006;49(2):191-203.

104.Bingham NC, Anderson KK, Reuter AL, Stallings NR, Parker KL. Selective loss of leptin receptors in the ventromedial hypothalamic nucleus results in increased adiposity and a metabolic syndrome. Endocrinology. 2008;149(5):2138-2148.

105. Bouret SG, Draper SJ, Simerly RB. Trophic action of leptin on hypothalamic neurons that regulate feeding. Science. 2004;304(5667):108-110.

106.Pinto S, et al. Rapid rewiring of arcuate nucleus feeding circuits by leptin. Science. 2004; 304(5667):110-115.

107. Horvath TL, et al. Synaptic input organization of the melanocortin system predicts diet-induced hypothalamic reactive gliosis and obesity. Proc Natl Acad SciU S A. 2010;107(33):14875-14880.

108. Castaneda TR, Tong J, Datta R, Culler M, Tschop $\mathrm{MH}$. Ghrelin in the regulation of body weight and metabolism. Front Neuroendocrinol. 2010;31(1):44-60.
109.Baicy K, et al. Leptin replacement alters brain response to food cues in genetically leptindeficient adults. Proc Natl Acad Sci U S A. 2007; 104(46):18276-18279.

110.Farooqi IS, Bullmore E, Keogh J, Gillard J, O'Rahilly S, Fletcher PC. Leptin regulates striatal regions and human eating behavior. Science. 2007;317(5843):1355.

111. Rosenbaum M, Sy M, Pavlovich K, Leibel RL, Hirsch J. Leptin reverses weight loss-induced changes in regional neural activity responses to visual food stimuli. J Clin Invest. 2008;118(7):2583-2591.

112.Rosenbaum M, et al. Low-dose leptin reverses skeletal muscle, autonomic, and neuroendocrine adaptations to maintenance of reduced weight. J Clin Invest. 2005;115(12):3579-3586.

113. Cavalcante JC, Bittencourt JC, Elias CF. Female odors stimulate CART neurons in the ventral premammillary nucleus of male rats. Physiol Behav. 2006;88(1-2):160-166.

114.Elias CF, et al. Leptin differentially regulates NPY and POMC neurons projecting to the lateral hypothalamic area. Neuron. 1999;23(4):775-786.

115. Cheung CC, Clifton DK, Steiner RA. Proopiomelanocortin neurons are direct targets for leptin in the hypothalamus. Endocrinology. 1997;138(10):4489-4492.

116. Munzberg H, Huo L, Nillni EA, Hollenberg AN, Bjorbaek C. Role of signal transducer and activator of transcription 3 in regulation of hypothalamic proopiomelanocortin gene expression by leptin. Endocrinology. 2003;144(5):2121-2131.

117. Elmquist JK, Ahima RS, Elias CF, Flier JS, Saper CB. Leptin activates distinct projections from the dorsomedial and ventromedial hypothalamic nuclei. Proc Natl Acad Sci U S A. 1998;95(2):741-746.

118. Elias CF, et al. Chemical characterization of leptinactivated neurons in the rat brain. J Comp Neurol. 2000;423(2):261-281.

119.Louis GW, Leinninger GM, Rhodes CJ, Myers MG Jr. Direct innervation and modulation of orexin neurons by lateral hypothalamic LepRb neurons. J Neurosci. 2010;30(34):11278-11287.

120. Hosoi T, Kawagishi T, Okuma Y, Tanaka J, Nomura $\mathrm{Y}$. Brain stem is a direct target for leptin's action in the central nervous system. Endocrinology. 2002; 143(9):3498-3504.

121.Leshan RL, et al. Ventral tegmental area leptin receptor neurons specifically project to and regulate cocaine- and amphetamine-regulated transcript neurons of the extended central amygdala. J Neurosci. 2010;30(16):5713-5723.

122. Ellacott KL, Halatchev IG, Cone RD. Characterization of leptin-responsive neurons in the caudal brainstem. Endocrinology. 2006;147(7):3190-3195.

123. Huo L, Gamber KM, Grill HJ, Bjorbaek C. Divergent leptin signaling in proglucagon neurons of the nucleus of the solitary tract in mice and rats. Endocrinology. 2008;149(2):492-497.

124. Huo L, Grill HJ, Bjorbaek C. Divergent regulation of proopiomelanocortin neurons by leptin in the nucleus of the solitary tract and in the arcuate hypothalamic nucleus. Diabetes. 2006;55(3):567-573.

125. Huo L, Munzberg H, Nillni EA, Bjorbaek C. Role of signal transducer and activator of transcription 3 in regulation of hypothalamic trh gene expression by leptin. Endocrinology. 2004;145(5):2516-2523. 